\title{
Moving towards implementation of a clinical ethics consultation program in Egyptian liver transplant units
}

This article was published in the following Dove Press journal:

Transplant Research and Risk Management

25 March 2010

Number of times this article has been viewed

\author{
A H El-Elemi' \\ G H El-Gazzaz ${ }^{2}$ \\ 'Forensic Medicine and Clinical \\ Toxicology Department, \\ ${ }^{2}$ Hepatobiliary and General \\ Surgery Department, Suez Canal \\ University, Ismailia, Egypt
}

Correspondence: $\mathrm{AH}$ El-Elemi Forensic Medicine and Clinical Toxicology Department, Suez Canal University, 58-60 Tarek Ebn Zeyad, Ismailia, Egypt Tel +2012370545 I

Fax +20643209448

Email azza.el.elemi@utoronto.ca
Abstract: The high prevalence of chronic liver disease in Egypt has led to increasing numbers of patients with end-stage liver disease in need of liver transplantation. To date, cadaveric liver transplantation is not legal in Egypt. However, introducing living-donor liver transplantation seems appropriate for patients who need transplantation. There are no clinical bioethicists in the Egyptian healthcare system. The idea of implementing an ethics consultation program has evolved as a response to complicated legal, ethical, and social dilemmas that accompany the transplantation process, especially in Egypt where organs are obtained by advertising without consideration of an acceptable level of risk to donors or recipients. Recommendations need to be made to start to implement bioethics consultation in liver transplantation units. To achieve this goal there is a need to develop training standards, credentials, and certification before embarking on clinical consultation to ensure good ethics practice in Egypt.

Keywords: live donor, liver transplantation, bioethics, donor, recipient

\section{Introduction}

The World Health Organization has declared hepatitis C virus (HCV) a global health problem, with approximately 3\% of the world's population (roughly 170-200 million people) infected. Most of the disease is clustered in developing countries, mainly Asia and Africa. ${ }^{1}$ Viral hepatitis is arguably the most significant public health problem now facing Egypt, a heavily populated country of about 80 million. HCV prevalence rates in the general population are estimated at between $10 \%$ and $15 \%$ in rural areas, with some age groups suffering from prevalence rates of up to $50 \%$. Incidence rates are estimated at 2-6 per 1000 per year, a level that will maintain prevalence rates of $5 \%-15 \%$ for the foreseeable future. ${ }^{1}$ The virus continues to be transmitted in medical and paramedical settings, as well as within communities and families. Approximately 5-7 million Egyptians carry antibodies for HCV and 3.3 million are chronically infected with HBV. Although not all persons infected with HBV and HCV go on to develop cirrhosis of the liver or other life-threatening sequelae, the medical and economic burden incurred by those who do is significant. Liver disease is a top cause of mortality in Egypt, and mathematical models predict an upsurge in cases of liver cirrhosis and liver cancer in years to come. ${ }^{2}$

This high prevalence of chronic liver disease in Egypt has led to increasing numbers of patients suffering from end-stage liver disease, necessitating liver transplantation. To date, cadaveric liver transplantation is not legal in Egypt and, until recently, liver transplant candidates had only one hope for cure, ie, to travel abroad seeking transplantation. However, this is not a feasible option for most 
Egyptian patients, and introducing living-donor liver transplantation has seemed to be the only logical choice to save many patients whom are in desperate need of a liver transplant.

Adult-to-adult right lobe living-liver donation was first reported in Japan by Yamaoka's group in $1994 .{ }^{3}$ US centers have performed more than 1700 living-donor procedures and worldwide there have been more than 10,000 procedures performed. Adult living-donor liver transplantation has remained controversial because of donor morbidity and highly publicized donor deaths, as well as concerns about inferior recipient outcomes. ${ }^{4}$

\section{Transplantation in Egypt}

Living-donor liver transplantation was first attempted in Egypt in 1991 by the surgical team at the National Liver Institute, Menoufiya University. At that time, only three living-donor liver transplantation procedures were performed, with the help of an overseas surgical team, and the longest recipient survival was 11 months. ${ }^{5}$ This pioneer work led to efforts to pass a law legalizing cadaveric organ donation, culminating in the 1992 decree permitting cadaveric organ harvesting from prisoners who were sentenced to death. Thereafter, the surgical team at the National Cancer Institute in Cairo performed two cadaveric liver transplantation procedures $^{6}$ but, unfortunately, both recipients died in the early postoperative period (Unpublished data).

As a result, the legislation on cadaveric donation was suspended indefinitely, which was a major setback for liver transplantation in Egypt. Throughout the 1990s, Egyptian patients continued to travel abroad seeking cadaveric liver transplantation, and a considerable number was lucky enough to receive transplants and return to Egypt in good health. ${ }^{7}$

Successfully transplanted patients, in addition to the ever increasing number of patients who are in desperate need of liver transplantation, have put enormous pressure on the Egyptian government to pass a law allowing cadaveric organ donation. ${ }^{6}$ In the late 1990 s, all efforts to pass a decree allowing cadaveric organ donation were sadly aborted in the Egyptian Parliament. Ironically, however, this major setback spearheaded several successful living-donor liver transplantation programs in Egypt. Many factors have contributed to the launch of these programs. Unfortunately, the increasing numbers of patients who are in desperate need of liver transplantation, along with the failure of the Egyptian government to legalize cadaveric organ donation, has created a very difficult situation in Egypt's healthcare system.

\section{Reasons for an ethics consultation program}

The idea of implementing an ethics consultation program has evolved in response to the complicated legal, ethical, and social dilemmas that accompany the process of donation and transplantation of organs, especially in Egypt where organs are obtained through advertising, without consideration of what is an acceptable level of risk to the donor and, as there is no accurate data about the extent of risk to a donor after sale of an organ, the harm to donors is underestimated. Donors prefer not to seek official help or medical assistance in the event of complications after donation because they have been coerced to sell a body organ for financial reasons (and often receive less payment than expected from recipients).

In Egypt, live-donor kidney transplantation is proving successful in both government and private hospitals, and living-liver transplantation continues to be a growing program, with cadaveric donation still under consideration. Also, there are concerns regarding the rapid unplanned expansion of living-donor liver transplantation programs in different medical centers in Egypt. Donor safety is of particular concern and, although donor mortality is very rare, it has been reported, and is an unacceptable catastrophe. ${ }^{6}$ The mortality of donors is about $0.2 \%-0.3 \%{ }^{8}$ If the recipient's body weight is much higher than that of the donor, the graft cannot meet the recipient's metabolic needs, thus resulting in small-for-size syndrome, ${ }^{9}$ or even death of the recipient. Therefore, making the living-donor process safe for both donors and recipients and enabling recipients to receive an adequate volume of graft for viable metabolism are serious problems.

Some of the ethical dilemmas that may need to be addressed relate to patient autonomy and decision-making, consent for donation, and ethical conflict related to the process of donation. Also, it may be in establishing a level of acceptable risk for the donor, triggers for a plan of care for the donor and the recipient, wanting assistance interacting with a difficult family, patient, or surrogate; medical risk for the donor, recipient and physician; and potential emotional triggers and conflicts to be resolved between team members in the liver unit. ${ }^{10}$

\section{Definition and description of clinical ethics consultation}

Bioethics is by nature a multidisciplinary enterprise that at various times addresses philosophical, legal, moral, social, and economic dimensions of healthcare. Bioethics in practice is "An engagement in moral development, a mutual 
process involving ourselves and those we serve" and "It is generally concerned with trying to understand the rightness or wrongness, the goodness or badness, of some action, policy, procedure or approach". ${ }^{11}$

Ethics consultation in healthcare is a service provided by an individual ethics consultant, ethics consultation team, or ethics committee to help patients, staff, and others resolve ethical concerns in a healthcare setting. ${ }^{12}$

Clinical ethics consultation is an important service that helps improve the quality of ethics practices and patient care. An ethical consultant is an expert in clinical ethics who provides ethics consultations and serves as an educator for hospital medical staff. ${ }^{13}$ A clinical ethics consultation program should facilitate discussion, analysis and understanding of ethical issues in patient care and research involving human subjects, and provide ethically appropriate recommendations for solving problems arising in healthcare practice and research. The role of the clinical bioethicist would include ensuring that a fair process of consultation, decision-making, and priority setting occurs. The practice of good clinical medicine requires some working knowledge about ethical issues such as informed consent, truth telling, confidentiality, end-of-life care, pain relief, and patient rights. ${ }^{14}$

The clinical ethics consultant must have advanced knowledge and skills across multiple areas, ${ }^{12}$ including:

- Moral reasoning and ethics theory

- Healthcare practices, especially clinical literacy

- Culture and religious issues

- Ethical issues and concepts in different areas (eg, shared decision-making, end-of-life care, confidentiality, professionalism, resource allocation, and research)

- Healthcare environment

- Health law.

Also, ethics consultants require specific skills including reaching consensus, communicating effectively and respectfully, analyzing any ethical concerns, evaluating consultations, providing education on ethics, using institutional resources effectively, being a good listener, and being able to facilitate and mediate formal and informal meetings.

\section{Goals of ethics consultation}

Ethics consultants contribute to achieving patient care goals by facilitating resolution of conflicts in a respectful atmosphere through a fair and inclusive decision-making process, helping institutions to shape policies and practices that conform with the highest ethical standards, and assisting individual persons with handling current and future ethical problems by providing education in healthcare ethics to the transplant team. ${ }^{15}$
It is generally agreed that ethics consultants can advise clinicians, patients, and family members on ethical matters including:

- Promoting practices consistent with high ethical standards

- Helping to foster consensus and resolving conflict in an atmosphere of respect

- Honoring participants authority and values in the decision-making process

- Educating participants to handle current and future ethical concerns. $^{12}$

In Egypt, organ transplantation presents difficult ethical and legal challenges for both the transplant community and society, so patients may not understand or may fear conflicts of interests with physicians, as well as the multiple commitments that can arise during the process of transplantation.

In situations like these, a bioethicist contributes to a transplant team by clarifying values held by various stakeholders or embodied in decisions and policies, conducting clinical consultations, developing and interpreting policy, and researching the ethics of innovations for rationing and increasing available supply of organs for transplantation. The bioethicist's interdisciplinary education, preparation, experience, and familiarity with ethics, law, sociology, philosophy, and skills of mediation, communication and ethical analysis contribute to addressing and resolving many issues in transplantation. ${ }^{15}$

Healthcare planners have duties to foster an ethical practice environment, and should hold physicians accountable for quality of care and not simply for performance. ${ }^{12}$ The patient-physician relationship and the principles that govern it should be central to the delivery of care. These principles include beneficence, honesty, confidentiality, privacy, non-maleficence, and autonomy and also advocacy when patients' interests could be endangered by arbitrary and unjust institutional procedures.

Two categories of donation by living persons can be distinguished in Egypt, ie, directed donation to a loved one or friend (directed related) and directed donation to a stranger, whereby donors choose to give to a specific person with whom they have no prior emotional connection (directed non-related).

Each type of donation prompts distinct ethical concerns. With directed donation to loved ones or friends, worries arise about the intense pressure that can be put on people to donate, leading those who are reluctant to do so to be coerced to donate ${ }^{16}$ In these cases, transplantation programs are typically willing to identify a plausible medical excuse, 
so that the person can bow out gracefully. Equally important, however, are situations in which people feel compelled to donate regardless of the consequences to themselves. Such a sense of compulsion is not unusual. ${ }^{17}$ In cases like these, simply obtaining the informed consent of the donor relative is insufficient. Physicians are obligated to prevent people from making potentially life-threatening sacrifices unless the chance of success is proportionately high and the clinical bioethicist in the transplant unit can help in resolving these ethical issues in a respectful milieu.

Directed non-related donation raises different ethical concerns. The altruism that motivates a person to make a potentially life-threatening sacrifice for a stranger calls for careful scrutiny. The clinical bioethicist and the transplantation team have an obligation to assess potential donors in all these respects and prevent donations that raise serious concern. ${ }^{16}$ This type of donation usually occurs when a patient advertises for an organ publicly, on newspapers or billboards, as is presently common practice in Egypt. Such advertising is not illegal, but has been strongly discouraged by the transplantation community. Two central objections are that the practice is unfair and that it threatens the view that an organ is a "gift of life", not a commodity to be bought and sold. ${ }^{17}$ The other substantial cause for concern about this type of donation is its potential for making possible the buying and selling of organs. These practices are strictly prohibited by law, yet they seem to be an inherent risk in directed donations to strangers. Wealthy patients in need of a transplant and healthy donors looking for a quick solution to financial problems will always be able to find ways around the existing legislation to solve their respective problems.

According to Gillon, the use of the "four-principles" approach in advocating the sale of organs for transplantation ${ }^{18}$ can be reasonable, especially in countries where selling of organs is the only feasible option for patients. Gillon argues that although in individual cases sale of body organs may be morally justified, respecting patient autonomy (both donors and recipients), producing net benefit over harm for donors and recipients, and involving at least no transgression of rightsbased justice, and enhancing distributive justice, nonetheless, overall, the likely dangers of financial exploitation and of postoperative harm to predominantly poor donors, the likely increased risks to recipients of contracting HIV and other infections, and the likely reduction in volunteer donors, will probably result in sufficient excess overall risk of harm over benefit to conclude that a legal ban would be justified. ${ }^{18}$

Therefore, the clinical ethics program will share in standardizing the process by using Gillon's four principles for evaluating potential donors, ensuring that independent advocates are assigned to help donors make an informed choice, developing mechanisms to deal with potential injury or death of the donor, setting standards for both directed related and directed non-related donation, and prohibiting transplantation when the chance of success is insufficient to justify the risks. Comprehensive overseeing is necessary if ethical pitfalls are to be adequately addressed. ${ }^{17}$

The ethics consultation program will help to support this environment in which the link between ethical practice and quality of healthcare services, especially in transplant units, is not well understood and not well appreciated. The healthcare system in Egypt needs to implement and establish an ethics consultation program in different hospital departments and, as a start, in the transplant units, where ethical problems raise a special need for establishing ethical policy.

The clinical bioethicist will clarify the values espoused by an institution and its employees, and how they are put in practice. Clash of values among the various stakeholders may create problems for the transplant team. A clinical bioethicist will approach such cases systematically, using theory related to transplantation to determine a morally satisfactory solution, ${ }^{15}$ according to the religious and social beliefs and norms of Egyptian patients.

An ethics consultation program will be comprised of experts who apply ethical reasoning to dilemmas encountered in medical practice around donation and transplantation in live donor transplant units. Also the clinical bioethicist plays an important role in education on bioethics for medical practitioners which will improve ethical practices in transplantation units.

When consulting, bioethicists need to be prepared to mediate conflicts and handle difficult situations. The ethics consultants might serve clinicians well by consulting on a proactive basis to avoid conflicts and by educating clinicians to develop mediation skills. ${ }^{19}$

\section{Conclusion}

Egypt has emerged as one of the most tolerant and modern Middle Eastern nations in the 21st century, is widely regarded as an influential leader in Middle Eastern affairs, and has made great steps in developing its health system in the last decade. As a part of this development, the system needs to be updated by mandatory implementation of a clinical ethics program in each hospital and healthcare organization to review and resolve ethical issues evolving in daily medical work, especially in living-donor liver transplantation units. 
Transplantation is a life-saving enterprise. It is a highly technical, surgical, and medical procedure practised in a situation surrounded by major ethical, legal, and social issues. Medical and technological advances often bring with them new issues that must be addressed if society is to continue to support organ transplantation. The role of the bioethicist is to act as a member of the health-care team in addressing the ethical issues as comprehensively as possible and not to avoid or ignore these ethical issues which threaten advances that have already been made. ${ }^{15}$

In Egypt, there are no clinical bioethicists in the healthcare system. Therefore, we need to make recommendations to implement a bioethics team to provide consultation to donors, recipients, and transplant teams in living-donor liver transplantation units. To achieve this goal we need a plan for training standards, credentials, and certification exams before being engaged in clinical consultation to ensure good practice of any clinical ethics consultation program. ${ }^{20}$

Because of the restricted cadaveric donor pool, livingdonor liver transplantation programs can only be justified when all the necessary institutional resources and surgical expertise are in place with the help and support of a clinical bioethicist, and when every effort continues to be made to enhance cadaveric organ donation in Egypt. It is hoped that this program will help the transplant team including clinicians, educators, nurses, technicians, social workers, and research scientists to address some of the challenging ethical dilemmas that confront them each day in transplant units.

\section{Disclosures}

The authors reports no conflicts of interest in this work.

\section{References}

1. "Hepatitis C," WHO Fact Sheet No 164 (revised Oct 2000), 2007. Available from: http://www.who.int/mediacentre/factsheets/fs164/en/, Accessed 3 Dec.

2. Dalglish S. In: Egyptian National Control Strategy for Viral Hepatitis 2008-2012. Arab Republic of Egypt, Ministry of Health and Population, National Committee for the Control of Viral Hepatitis, April 2008.
3. Yamaoka T, Washida M, Honda K, et al. Liver transplantation using a right lobe graft from a living related donor. Transplantation. 1994;57:1127-1129.

4. Brown RS. The ethics of living-donor liver transplantation: Safe and life saving. American Gastroenterological Association; March 2007. Available from: http://www.gastro.org/wmspage.cfm?parm1=3535.

5. Habib NA, Higgs BD, Marwan I, et al. Living-related liver transplantation in Africa. Int Surg. 1993;78:121-123.

6. Khalaf H, El-Meteini M, El-Gazzaz G, et al. Evolution of living donor liver transplantation in Egypt. Saudi Med J. 2005;26:(9).

7. Khalaf H, Farag S, El-Hussainy E. Long-term follow-up after liver transplantation in Egyptians transplanted abroad. Saudi Med J. 2004;25:1931-1934.

8. Hwang S, Lee SG, Lee YJ, et al. Lessons learned from 1,000 living donor liver transplantations in a single center: How to make living donations safe. Liver Transpl. 2006;12:920-927.

9. Tanaka K, Ogura Y. "Small-for-size graft" and "small-for-size syndrome" in living donor liver transplantation. Yonsei Med J. 2004;45:1089-1094.

10. Brown RS Jr, Lake JR. The survival impact of liver transplantation in the MELD era, and the future for organ allocation and distribution. Am J Transplant. 2005;5:203-204.

11. Andre J. Bioethics as Practice. Chapel Hill, NC: University of North Carolina Press; 2002;25:44.

12. Fox E, Berkowitz KA, Chanko BL, Powell T. Integrated Ethics: "Improving Ethics Quality in Health Care (Veteran's Administration in the US): Ethics consultation, pages 1-24. Available from: http://www. ethics.va.gov/integratedethics. Accessed 3 Dec.

13. Pearlman RA. Ethics Committees and Ethics Consultation. Ethical Topic in Medicine. Washington, DC: University of Washington; 1998.

14. Jonsen AR, Siegle M, Winslade WJ. Clinical Ethics: A Practical Approach to Ethical Decisions in Clinical Medicine. 4th ed. New York, NY: McGraw-Hill Inc.; 1998.

15. Wright L, Ross K, Daar AS. The roles of a bioethicist on an organ transplantation service. American Journal of Transplantation. 2005; 5(4 Pt 1):821-826.

16. Abecassis M, Adams M, Adams P, et al. Consensus statement on the live organ donor. JAMA. 2000;284:2919-2926.

17. Truog Robert $\mathrm{D}$. The ethics of organ donation by living donor. N Engl J Med. 2005;353:444-446.

18. Gillon R. Transplantation and ethics. In: Thomasma D, Kushner T, editors. From Birth to Death - Science and Bioethics. Cambridge, UK: Cambridge University Press; 1996.

19. DuVal G, Sartorius L, Clarridge B, Gensler G, Danis M. What triggers requests for ethics consultations? J Med Ethics. 2001;27(Suppl 1):i24-i29.

20. Fox MD, McGee G, Caplan A. Paradigms for clinical ethics consultation practice. Cambr Q Healthc Ethics. 1998;7:308-314.
Transplant Research and Risk Management

\section{Publish your work in this journal}

Transplant Research and Risk Management is an international, peerreviewed open access journal focusing on all aspects of transplantation and risk management to achieve optimal outcomes in the recipient improving survival and quality of life. The journal welcomes submitted papers covering original research, basic science, clinical studies,

\section{Dovepress}

reviews \& evaluations, guidelines, expert opinion and commentary, case reports and extended reports. The manuscript management system is completely online and includes a very quick and fair peer-review system, which is all easy to use. Visit http://www.dovepress.com/ testimonials.php to read real quotes from published authors. 